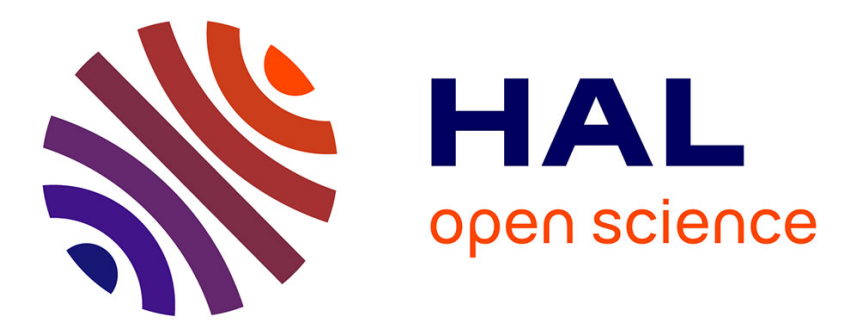

\title{
An overview on machine learning-based solutions to improve lightpath QoT estimation
}

Reda Ayassi, Ahmed Triki, M Laye, Noel Crespi, Roberto Minerva, Clara

\author{
Catanese
}

\section{- To cite this version:}

Reda Ayassi, Ahmed Triki, M Laye, Noel Crespi, Roberto Minerva, et al.. An overview on machine learning-based solutions to improve lightpath QoT estimation. ICTON 2020: 22nd International Conference on Transparent Optical Networks, Jul 2020, Bari (online), Italy. pp.1-4, 10.1109/ICTON51198.2020.9203755 . hal-03161225

\section{HAL Id: hal-03161225 \\ https://hal.science/hal-03161225}

Submitted on 5 Mar 2021

HAL is a multi-disciplinary open access archive for the deposit and dissemination of scientific research documents, whether they are published or not. The documents may come from teaching and research institutions in France or abroad, or from public or private research centers.
L'archive ouverte pluridisciplinaire HAL, est destinée au dépôt et à la diffusion de documents scientifiques de niveau recherche, publiés ou non, émanant des établissements d'enseignement et de recherche français ou étrangers, des laboratoires publics ou privés. 


\title{
An Overview on Machine Learning-Based Solutions to Improve Lightpath QoT Estimation
}

\author{
R. Ayassi ${ }^{1,2}$, A. Triki ${ }^{1}$, M. Laye ${ }^{1}$, N. Crespi ${ }^{2}$, R. Minerva ${ }^{2}$, C. Catanese $^{1}$ \\ ${ }^{\text {I}}$ Orange Labs, Lannion, France \\ ${ }^{2}$ Institut Polytechnique de Paris, Institut Mines-Telecom, Telecom SudParis, France \\ E-mail: reda.ayassi@orange.com
}

\begin{abstract}
Estimating lightpath Quality of Transmission (QoT) is crucial in network design and service provisioning. Recent studies have turned to Machine Learning (ML) techniques to improve the accuracy of QoT estimation. We distinguish two categories of solutions: the first category aims to build ML-based QoT estimation models that outperform the analytical model while the second category uses ML algorithms to reduce uncertainties on parameters provided as input to analytical model. In this overview, we describe the solutions in each category and discuss their practical feasibility and added benefit for operational networks.
\end{abstract}

Keywords: Machine Learning, WDM networks, QoT.

\section{INTRODUCTION}

Optical transport networks have steadily evolved through a number of technological advances such as coherent transmission, flexible modulation and tunable transponder. This has resulted in a plethora of new parameters and configurations to be considered for network design and operation, which makes estimation of the Quality of Transmission (QoT) difficult and complex task.

Currently, QoT estimation is based on analytical models that approximate linear and non-linear impairments. Each analytical model relies on a set of assumptions and requires the knowledge of a set of parameters. The Gaussian Noise (GN) model [1], for instance, is based on three assumptions : i) the nonlinear effects are small enough to be modeled as perturbations; ii) the transmitted signal behaves as stationary Gaussian noise; and iii) the nonlinear disturbance is manifested as additive Gaussian white noise. In optical systems where these assumptions are validated, SNR prediction precision is around $1 \mathrm{~dB}$ [2]. To cope with the lack of accuracy of the QoT estimation due to the violation of assumptions and an imprecise knowledge of parameter values, design margins are added by operators and vendors [3]. QoT overestimation can lead to unfeasible lightpaths during network operation, while QoT underestimation can generate greater expenditure on network equipment.

Recent studies on improving the accuracy of QoT estimation have focused on Machine Learning (ML) solutions. Based on data collected from the optical network, ML algorithms are able to capture the behavior of a physical phenomenon implicitly, simply through the variations in the data [4].

We summarize recent works that apply ML methods to estimate the QoT, and propose a method to classify them into two categories according to the intended usage of ML. The first category uses ML to create a model to estimate QoT metrics and assess lightpath feasibility while considering a specific set of parameters. By learning the effect of each transmission parameter on the QoT, these solutions are designed to offer an alternative to analytical models. The second category deals with the problem of parameter uncertainty. ML algorithms are therefore utilized to accurately compute the parameters that will be used as input for the analytical model.

This paper is organized as follows. In section 2, we present the solutions of each category. In section 3 we discuss the results of this survey, and comment on the practical feasibility of the approaches. Section 4 concludes the paper and suggests likely avenues for future efforts.

\section{ML-BASED SOLUTIONS' DESCRIPTION}

\subsection{FOR THE ESTIMATION OF LIGHTPATH QOT}

The authors in [5] use an Artificial Neural Network (ANN) model to assess the feasibility of potential lightpaths based on a Q-factor threshold. The model takes as input features that are related to the lightpath but do not depend on the physical layer impairments (see Table 1). In addition to achieving an accuracy score between $92 \%$ and $95 \%$, the authors claim that their approach is rapid and self-adaptive, as it can adapt to the behavior of the network in which it is trained. This study also evaluates the model's performance during lightpath provisioning. It proves that using the ML-based model for QoT estimation together with a routing algorithm leads to fewer blocked lightpaths compared to only using an analytical model.

Random Forest and K-Nearest-Neighbors (KNN) classifiers are used in [6] to predict the probability that the BER of a lightpath will exceed a given threshold (or not). The model's input features consist of the end-to-end parameters of the lightpath, as well as the parameters of the neighboring channels in the transmission in order to consider cross-channel impairments. The results prove to have an accuracy of up to $96 \%$ on several topologies. 
This paper also evaluates the impact of various factors on the QoT estimation, such as dataset size, feature selection and dataset collection methods (e.g., the use of probes). This comprehensive study takes into consideration the variation of lightpath routes and parameters, and the proposed model provides probability forecasts used to sort potential lightpaths according to their QoT and feasibility.

In [7], a regression ANN is proposed to predict the Q-factor of lightpaths in optical systems with different configurations in terms of fiber type, modulation and span number (between 2 and 4 spans). Contrary to [5] and [6], the output of the model is the value of the Q-factor. The main problem in ML based QoT estimators is the generalization of the model. A model trained on a specific optical system might not be suitable in a different system. Therefore, the authors propose a solution based on transfer learning. First the model is pre-trained on samples from an initial network configuration. Then, for each different system, the model is retrained on a small number of training samples in order to learn the characteristics of the target network. The results show that the ANN model is able to predict the Q-factor with a maximum error of $0.2 \mathrm{~dB}$ on the initial system. Moreover, the transfer learning technique can achieve similar results on different systems $(0.67 \mathrm{~dB}$ of max error on the worst case system), and is also more accurate and faster than simply retraining the model from scratch.

An ANN is proposed in [8] to estimate nonlinear SNR $\left(\mathrm{SNR}_{\mathrm{nl}}\right)$ exclusively. The particularity of this paper is that three sets of features are combined. The first set of features consists of noise covariance coefficients calculated from constellations detected by the Digital Signal Processor (DSP). The second set is the $\mathrm{SNR}_{\mathrm{nl}}$ output of two variants of GN-based analytical models (coherent and incoherent). The third set is related to network level features. Table 1 lists the most important of these features. After testing different combinations of these features, the results of the ANN algorithm show that the best performance $\left(0.33 \mathrm{~dB}\right.$ of $\mathrm{SNR}_{\mathrm{nl}}$ deviation) is achieved using all of them at the same time. The study goes further to check the model's ability to adapt to optical power parameter uncertainty. The ANN trained with all features learns to rely more on the certain parameters in order to give the same level of accuracy. This work proposes an interesting solution that uses ML alongside monitoring and analytical tools.

In [9], the goal is to tackle QoT estimation in Spectrally-Spatially Flexible Optical Networks (SS-FONs) with multicore fibers (MCFs), where inter-core cross talk is a serious impairment. A deep graph convolutional network is used to represent the features of the deployed lightpaths in order to model inter-channel interferences. The graph is composed of an adjacency matrix mapping out the lightpaths that share at least one link, in addition to a vector of end-to-end parameters for each lightpath, including MCF characteristics such as the allocated core number. The model checks if the deployment of a new lightpath will destabilize the previous network state by comparing the BER of each lightpath in the new network state with a given threshold. The model uses BER measurements of already-deployed lightpaths as a feature, assuming that they are available through a closed control loop. The model is capable of correctly classifying up to $97 \%$ of the new lightpaths.

\subsection{TO REDUCE UNCERTAINTY ON PARAMETERS}

The researchers in [10] propose collecting the QoT measurements $\left(\mathrm{Q}_{\mathrm{ac}}\right)$ of initial lightpaths during the greenfield phase. The corresponding analytical QoT $\left(\mathrm{Q}_{\mathrm{an}}\right)$ is calculated using an analytical model. Assuming that there is an uncertainty in some network parameters, the $\mathrm{Q}_{\mathrm{an}}$ must deviate from the $\mathrm{Q}_{\mathrm{ac}}$. The difference between the values of $\mathrm{Q}_{\mathrm{an}}$ and $\mathrm{Q}_{\mathrm{ac}}$ is used by a gradient descent algorithm to update the uncertain parameters and gets iteratively reduced until it becomes minimal. The new values are then used in the brownfield phase with analytical models to output a more precise QoT. This method was tested considering the input power and the noise figure as the uncertain parameters. A synthetic dataset was simulated using two analytical models (SAMBA and EGN) by selecting an initial distribution of parameters, and then shifting the distribution to generate uncertainty. The algorithm was proven to reduce the QoT error by up to $1.9 \mathrm{~dB}$ and $4.18 \mathrm{~dB}$ with SAMBA and EGN, respectively. Different distribution configurations were tested and the effect of dataset size was evaluated. The drawback of this method is that the derivatives of the analytical formulas have to be computed, which might be impractical especially in the case of black box analytical tools.

An elaborate closed loop controller architecture for optical networks is proposed in [11]. It uses feedback from network measurements to improve the QoT estimation. Their QoT estimation module uses an analytical model of the physical layer to calculate the Q-factor and the margins of the candidate lightpath, which will later be used for decision making by the routing deployment module. Once a lightpath is provisioned, its QoT is measured and is then used to adjust the parameters of the physical layer model. This adjustment is achieved by the following method: the difference between the estimated and the measured values is calculated, and then the parameters are updated according to their contribution in the difference. To test their method, authors use data collected from a testbed in which an initial probing phase is used to reduce uncertainty in the noise figure parameter, and then both noise figure and nonlinear coefficient uncertainties are reduced iteratively using the aforementioned method. The continuous update of the parameters makes this solution able to adapt to changes in the network.

The authors in [12] propose two different approaches for QoT estimation. The first is a purely ML based estimator that assesses SNR value. The second approach iteratively reduces the uncertainty of the parameters required as the input of an analytical model, improving the model's QoT estimation similarly to the solution in [10]. However in this case, the analytical model is considered as a black box. This means that traditional 
optimization algorithms cannot be used, since it is not possible to compute derivatives of the error function. This study therefore proposes to use nonlinear fitting techniques to overcome this problem. In each iteration, a nonlinear curve is fitted to the data, as a function of the missing parameters. The parameters are then updated to reduce the distance between the curve and the data. This method is flexible and analytical-model agnostic. It performs slightly better (its design margin reduction is up to $1.95 \mathrm{~dB}$ ) than the straightforward ML based regression estimator (whose design margin reduction is up to $1.8 \mathrm{~dB}$ ), but requires more training time.

\section{DISCUSSION}

Table 1: Characteristics of ML-based QoT estimation models

\begin{tabular}{|c|c|c|c|c|c|}
\hline Ref & $\begin{array}{l}\text { ML } \\
\text { methods }\end{array}$ & Input data & Output data & Dataset & Performance \\
\hline \multicolumn{6}{|c|}{ Estimation of lightpath $Q o T$} \\
\hline [5] & $\begin{array}{l}\text { Feed-forward } \\
\text { NN }\end{array}$ & $\begin{array}{l}\text { Length of the lightpath, number of EDFA in the path, } \\
\text { maximum link length of the lightpath, degree of } \\
\text { destination node, the wavelength used, ANN bias. } \\
\text { Asm.: QoT data of previously established connections } \\
\text { is provided and used to train the model }\end{array}$ & $\begin{array}{l}\text { Classification } \\
\text { of Q-factor } \\
\text { based on a } \\
\text { threshold }\end{array}$ & $\begin{array}{l}\text { Synthetic: } \\
\text { generated using } \\
\text { Q-factor model }\end{array}$ & $\begin{array}{l}\text { Accuracy close to } 92 \%- \\
95 \% \text { compared with Q- } \\
\text { factor model. }\end{array}$ \\
\hline [6] & $\begin{array}{l}\text { KNN, } \\
\text { Random } \\
\text { Forrest }\end{array}$ & $\begin{array}{l}\text { Lightpath length, longest link length, number of links, } \\
\text { traffic volume, modulation format, left/right } \\
\text { guardband, left/right traffic volume, left/right } \\
\text { modulation format. } \\
\text { Asm.: EDFAs are identical, equally spaced and have } \\
\text { fixed gain and NF. }\end{array}$ & $\begin{array}{l}\mathrm{P}_{\text {pos }} \text { probability } \\
\text { that the BER of } \\
\text { the lightpath } \\
\text { exceeds a } \\
\text { predefined } \\
\text { threshold }\end{array}$ & $\begin{array}{l}\text { Synthetic: } \\
\text { generated using } \\
\text { BER E-Tool }\end{array}$ & $\begin{array}{l}\text { Accuracy up to } 96 \% \text { on } \\
\text { certain topologies }\end{array}$ \\
\hline [7] & ANN & $\begin{array}{l}\text { Output power and modulation format for each of the } \\
11 \text { channels considered by the study. } \\
\text { Asm.: span loss is compensated by EDFA. }\end{array}$ & Q-factor value & $\begin{array}{l}\text { Experimental } \\
\text { data from a } \\
\text { testbed }\end{array}$ & $\begin{array}{l}\text { Q-factor max error: } 0.2 \mathrm{~dB} \\
\text { on initial system. Up to } 0.6 \\
\text { dB on different systems }\end{array}$ \\
\hline [8] & ANN & $\begin{array}{l}\text { Noise covariance, number of spans, max span length, } \\
\text { average power, launch power, link length, chromatic } \\
\text { dispersion, average fiber gamma, average fiber alpha, } \\
\text { number of channels. }\end{array}$ & Nonlinear SNR & $\begin{array}{l}\text { Synthetic: } \\
\text { simulated using } \\
\text { split step } \\
\text { Fourier method } \\
\end{array}$ & $\begin{array}{l}0.33 \mathrm{~dB} \text { of } \mathrm{SNR}_{\mathrm{nl}} \text { deviation } \\
\text { using combination of all } \\
\text { features }\end{array}$ \\
\hline [9] & $\begin{array}{l}\text { Deep graph } \\
\text { convolution- } \\
\text { al neural } \\
\text { network }\end{array}$ & $\begin{array}{l}\text { Channel adjacency matrix, lightpath length, max link } \\
\text { length, central frequency, number of slots, core } \\
\text { identifier, modulation format, number of EDFA, } \\
\text { number of links, BER of the deployed lightpaths. } \\
\text { Asm.: same fiber core is allocated along the lightpath }\end{array}$ & $\begin{array}{l}\text { BER } \\
\text { classification } \\
\text { based on } \\
\text { threshold }\end{array}$ & Synthetic & $\begin{array}{l}\text { Accuracy rates between } \\
92 \% \text { and } 97 \%\end{array}$ \\
\hline \multicolumn{6}{|c|}{ Reduce uncertainty on parameters } \\
\hline [10] & $\begin{array}{l}\text { Gradient } \\
\text { descent }\end{array}$ & $\begin{array}{l}\text { Target SNR value, initial noise figure value, initial } \\
\text { input power value. } \\
\text { Asm.: same distance between EDFAs and } \\
\text { amplification gain is perfectly flat. }\end{array}$ & $\begin{array}{l}\text { Noise figure, } \\
\text { input power }\end{array}$ & $\begin{array}{l}\text { Synthetic: } \\
\text { generated using } \\
\text { SAMBA and } \\
\text { EGN models }\end{array}$ & $\begin{array}{l}\text { Error reduced by up to } 1.9 \\
\mathrm{~dB} \text { and } 4.18 \mathrm{~dB} \text { compared } \\
\text { with SAMBA and EGN } \\
\text { respectively }\end{array}$ \\
\hline [11] & $\begin{array}{l}\text { Custom } \\
\text { linear } \\
\text { regression }\end{array}$ & $\begin{array}{l}\text { Target Q-factor value, initial noise figure value, initial } \\
\text { nonlinear coefficient value. } \\
\text { Asm.: EDFA gain in the ROADM compensates for } \\
\text { span losses and the losses inside the ROADM. }\end{array}$ & $\begin{array}{l}\text { Noise figure, } \\
\text { nonlinear } \\
\text { coefficient }\end{array}$ & $\begin{array}{l}\text { Experimental } \\
\text { data from a } \\
\text { testbed }\end{array}$ & $\begin{array}{l}\text { Error reduced from } 1.4 \mathrm{~dB} \\
\text { to } 0.6 \mathrm{~dB}\end{array}$ \\
\hline [12] & $\begin{array}{l}\text { Nonlinear } \\
\text { curve fitting }\end{array}$ & $\begin{array}{l}\text { Target SNR value, initial values of attenuation, } \\
\text { dispersion and non-linear coefficients. } \\
\text { Asm.: EDFA compensates for span loss. }\end{array}$ & $\begin{array}{l}\text { Attenuation, } \\
\text { dispersion and } \\
\text { non-linear } \\
\text { coefficients }\end{array}$ & Synthetic & $\begin{array}{l}\text { Design margin reduction is } \\
\text { up to } 1.95 \mathrm{~dB}\end{array}$ \\
\hline
\end{tabular}

In Table 1, we summarize the characteristics of the solutions mentioned in Section 2. We observe that most models achieve satisfying results in terms of accuracy and error reduction. However there are still concerns about their practical feasibility in operational networks, especially, in terms of generalization in a large scale network, data collection and deployment cost.

The estimation of the QoT requires the knowledge of many equipment parameters which may explode the list of features of the dataset. Therefore, studies as shown in Table 1 define assumptions (Asm). In some cases, these assumptions can mask the engineering complexity as in [6] and [10] where EDFA are assumed to be equally spaced and have the same gain. In other cases, the studies assume the existence of some features that are hard to obtain such as [5] that assumes the knowledge of the OSNR of the pre-established lightpath. These assumptions limit the practical feasibility of the solutions in a real network and their generalization to address any optical network topology and configuration. Moreover, relying on synthetic data conceals issues related to the collection and availability of data in a real optical network. In addition to that, data collected from operational networks may not be suited for learning tasks as it may not capture enough variation to train the model, for example with regards to data related to the case of unfeasible lightpaths.

From another perspective, any assessment of the accuracy of the proposed ML-based solutions should also consider their implementation cost. A dedicated monitoring and control architecture, such as that proposed in [13] must be adopted in order to support ML methods, which incurs additional costs. For instance, in case where parameters could not be obtained in operational networks, dedicated hardware should be installed for monitoring 
(e.g., mini optical spectrum analyzer to measure OSNR). Studies [6] and [9] seem to be the most pragmatic in this regards, since they use operationally available end-to-end parameters, to estimate a fairly reliable indicator (i.e., pre FEC-BER). Given the satisfying results offered by analytical models as shown in [2], the question from an operator's point of view is whether the reported improvement in QoT accuracy can justify the additional costs of deploying ML-based solutions.

We propose that the use of ML algorithms to improve QoT estimation should focus on supporting analytical models rather than on proposing an alternative to these models. Indeed, a purely ML based estimation requires juggling extensive data collection and induces generalization concerns. Therefore, it would be better to use ML to reduce uncertainty on some parameters or to assess specific impairments in order to improve the precision of analytical model that could dispense with monitoring those parameters that are difficult to obtain or which cannot be measured.

\section{CONCLUSION}

We provide an overview of the ML-based studies that estimate the QoT in optical networks. We classify the proposed solutions into two classes. The first class uses ML as a quick and reliable standalone tool to estimate the QoT and check lightpath feasibility, while the second uses ML to reduce the uncertainty of network parameters and provide accurate inputs to the analytical tools. While the results of the proposed algorithms are generally satisfactory, some concerns remain regarding their ability to generalize in order to support complex optical transport network topologies and various equipment configurations. Moreover, the additional cost related to the data monitoring and implementation of these solutions calls into question their practicability and their actual added value. From our perspective, we believe that ML-based solution should be used together with an analytical modelbased tool to assess specific impairments that are difficult to model analytically and to reduce the uncertainty of some parameters that vary during the life-cycle of the network.

\section{REFERENCES}

[1] P. Poggiolini et al., "The GN-Model of Fiber Non-Linear Propagation and its Applications," J. Light. Technol., vol. 32, no. 4, pp. 694-721, Feb. 2014, doi: 10.1109/JLT.2013.2295208.

[2] A. Ferrari et al., "Experimental Validation of an Open Source Quality of Transmission Estimator for Open Optical Networks," in Optical Fiber Communication Conference (OFC) 2020, San Diego, California, 2020, p. W3C.2, doi: 10.1364/OFC.2020.W3C.2.

[3] Y. Pointurier, "Design of Low-Margin Optical Networks," J. Opt. Commun. Netw., vol. 9, no. 1, p. A9, Jan. 2017, doi: 10.1364/JOCN.9.0000A9.

[4] S. Shalev-Shwartz et al., Understanding Machine Learning: From Theory to Algorithms. Cambridge: Cambridge University Press, 2014.

[5] T. Panayiotou et al., "Performance Analysis of a Data-Driven Quality-of-Transmission Decision Approach on a Dynamic Multicast-Capable Metro Optical Network," J. Opt. Commun. Netw., vol. 9, no. 1, p. 98, Jan. 2017, doi: 10.1364/JOCN.9.000098.

[6] C. Rottondi et al., "Machine-Learning Method for Quality of Transmission Prediction of Unestablished Lightpaths," J. Opt. Commun. Netw., vol. 10, no. 2, p. A286, Feb. 2018, doi: 10.1364/JOCN.10.00A286.

[7] W. Mo et al., "ANN-Based Transfer Learning for QoT Prediction in Real-Time Mixed Line-Rate Systems," in Optical Fiber Communication Conference, San Diego, California, 2018, p. W4F.3, doi: 10.1364/OFC.2018.W4F.3.

[8] Q. Zhuge et al., "Application of Machine Learning in Fiber Nonlinearity Modeling and Monitoring for Elastic Optical Networks," J. Light. Technol,, vol. 37, no. 13, pp. 3055-3063, Jul. 2019, doi: 10.1109/JLT.2019.2910143.

[9] T. Panayiotou et al., "Machine Learning for QoT Estimation of Unseen Optical Network States," in Optical Fiber Communication Conference (OFC) 2019, San Diego, California, 2019, p. Tu2E.2, doi: 10.1364/OFC.2019.Tu2E.2.

[10] E. Seve et al., "Learning Process for Reducing Uncertainties on Network Parameters and Design Margins," J. Opt. Commun. Netw., vol. 10, no. 2, p. A298, Feb. 2018, doi: 10.1364/JOCN.10.00A298.

[11] M. Bouda et al., "Accurate Prediction of Quality of Transmission Based on a Dynamically Configurable Optical Impairment Model," J. Opt. Commun. Netw., vol. 10, no. 1, p. A102, Jan. 2018, doi: 10.1364/JOCN.10.00A102.

[12] I. Sartzetakis et al., "Accurate Quality of Transmission Estimation With Machine Learning,” J. Opt. Commun. Netw., vol. 11, no. 3, p. 140, Mar. 2019, doi: 10.1364/JOCN.11.000140.

[13] K. Christodoulopoulos et al., "Toward efficient, reliable, and autonomous optical networks: the ORCHESTRA solution [Invited]," J. Opt. Commun. Netw., vol. 11, no. 9, p. C10, Sep. 2019, doi: 10.1364/JOCN.11.000C10. 